\title{
INNOVATIVE LOOP DESIGN FOR EFFECTIVE \& EFFICIENT SPACE CLOSURE: THE SWAN LOOP
}

\author{
Dr. Sarvraj Kohli, ${ }^{1}$ Dr. Shyamala Chandrasekhar, ${ }^{2}$ Dr. KK Shantha Sundari, ${ }^{3}$ \\ Dr. Sumathi Felicita, ${ }^{4}$ Dr. Virinder S. Kohli ${ }^{5}$ \\ 1. Former PG Student, Dept of Orthodontics, Saveetha Dental College, Chennai, India \\ 2. Professor, Dept of Orthodontics, Saveetha Dental College, Chennai, India \\ 3. Professor \& HOD, Dept of Orthodontics, Saveetha Dental College, Chennai, India \\ 4. Assistant Professor, Dept of Orthodontics, Saveetha Dental College, Chennai, India \\ 5. Professor \& HOD, Dept of Orthodontics, Hitkarini Dental College, Jabalpur, India
}

Correspondence : sarvraj.kohli@gmail.com

\section{ABSTRACT}

Various space closing mechanics have been advocated for fixed appliance orthodontic mechanotherapy, ranging from the use of micro-implants to employing specially designed space closing loops. These techniques have their inherent advantages and disadvantages; primarily with friction-less mechanics it is the intricate wire-bending which dissuades the clinician from everyday usage. Presented in this report is a proposal of an innovative loop which can be readily assimilated in clinical orthodontic practice and is both efficient and effective for controlled space closure scenarios.

Key-words: archwire loop, orthodontic mechanotherapy, space closure, TMA

\section{INTRODUCTION:}

Contemporary comprehensive fixed appliance preadjusted edgewise orthodontic mechanotherapy can be broadly divided into three stages: a) leveling and aligning, b) space closure and c) finishing and detailing. ${ }^{1}$ Of these probably the second stage i.e. space closure has received maximum attention by researchers and clinicians alike. Techniques employed for space closure can be sub-divided into those utilizing friction mechanics or frictionless mechanics. ${ }^{2,3}$

The introduction of the TMA alloy by Burstone, ushered in a new era in frictionless mechanics (commonly referred to as loop mechanics) as more complex loop designs could be fabricated without fear of fatigue build-up in the wire while at the same time it ensured a high activation potential and a low load deflection ratio. ${ }^{4}$

Numerous loop designs have been suggested for space closure. ${ }^{5,6,7,8,9,10}$ Of these the most scientifically designed loop is the Opus loop by Siatkowski using the Haack's equation and Finite Element Modeling. ${ }^{5,6}$ However because of its increased vertical length it has been observed to impinge on the gingival and muco-labial mucosa. To deal with this, a loop was designed for space closure in continuous arch mechanics by the authors that would deliver a low deflection ratio, high activation potential, and would be comfortable for the patient and easy to fabricate for the clinician.

\section{Loop Design}

The loop was fashioned from 0.017" x 0.025" TMA wire by incorporating two vertical loops bent at an angle of $45^{\circ}$ to each other with a helix at the center. The height of the loops is $7 \mathrm{~mm}$ and the diameter of the helix is $1.5 \mathrm{~mm}$ (Figure 1). Pre-activation alpha and beta bends are incorporated into the wire with regard to space closure considerations. For Group A anchorage requirement cases, $\alpha=25^{\circ}$ and $\beta=35^{\circ}$, in Group B anchorage requirement cases both $\alpha$ and $\beta$ bends are kept equal, while in Group $C$ anchorage requirement cases $\alpha=35^{\circ}$ and $\beta=25^{\circ}$. Upon testing the loop design in the Loop software ${ }^{11}$ it was observed that on activation the loop exerted a Moment to Force (M/F) ratio close to $10 / 1$ (Figure 2). Another essential consideration is that the loop position should be off centered towards the segment that is treated as the anchor unit.

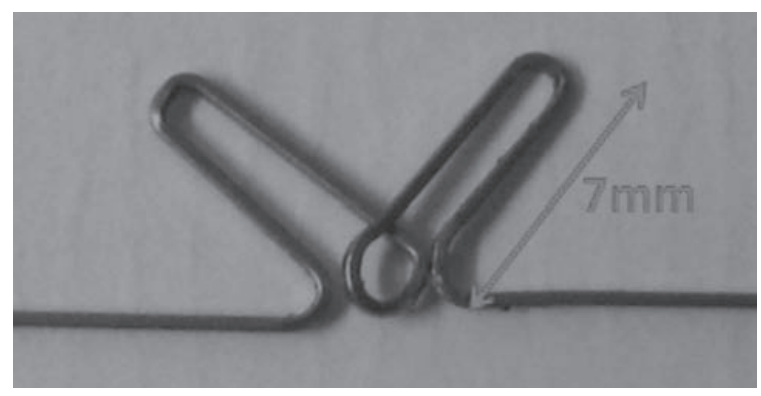

Figure 1: Swan Loop Design 


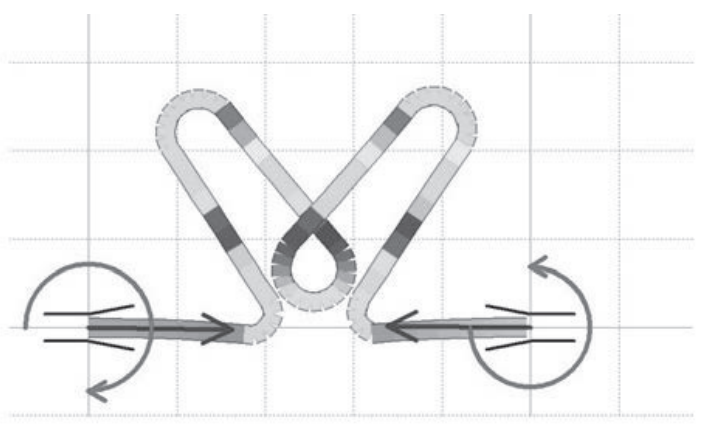

Fig 2: Stimulation of Swan Loop in Loop software

\section{Advantage:}

The Swan Loop provides the following benefits over contemporary loop designs utilized in the continuous archwires:

1. Efficient and effective control of both anterior and posterior units.

2. As greater activation is possible, the orthodontist needs to see the patient at an interval of 5-6 weeks.

3. As the length of wire employed is greater it offers a lower load-deflection ratio.

4. Enhanced control over final root positioning of the retracted segments as the $\mathrm{M} / \mathrm{F}$ ratio progressively increases as the spring deactivates.

5. Improved oral hygiene and patient comfort because of less impingement in the oral mucosa.

6. There are no issues related to poking of wires as is commonly observed in sliding mechanics.

The Swan Loop presents a new design in frictionless loop mechanics to be employed on a continuous archwire mechanics and provides greater control over the segments and better results.

\section{CASE REPORT:}

The patient was a 17 years old girl with an unremarkable medical history. She had a Class I bimaxillary dentoalveolar protrusion, and a slightly convex facial profile. Her mandible appeared to be slightly recessive. Her chief concerns were "my teeth appear to be forwardly placed".

Facial and intra-oral photographs demonstrated a convex facial profile (Fig. 3). She was unable to close her lips without mentalis strain. The occlusion showed an Angle's Class I molar relation on both right and left sides and proclined upper and lower anteriors (Fig. 4). There was an overjet of $2 \mathrm{~mm}$ and overbite of $2 \mathrm{~mm}$. No posterior or anterior crossbites were seen.

The pretreatment lateral cephalogram and its tracing (Figure 5) revealed a mild skeletal Class II relationship $\left(A N B=5^{\circ}\right)$ attributable to a orthognathic maxilla $\left(\mathrm{SNA}=83^{\circ}\right)$ and a mildly retrognathic mandible $\left(\mathrm{SNB}=78^{\circ}\right)$.
An average growth pattern $\left(\mathrm{Go}-\mathrm{Gn}=34^{\circ}, \quad \mathrm{FMA}=26^{\circ}\right.$ ) was observed and Wit's appraisal of $5 \mathrm{~mm}$ confirmed a skeletal Class II alveolar imbalance. A Z angle of $69^{\circ}$ confirmed a mildly protruded soft-tissue overlay. Upper incisors were proclined (Upper 1 to $\mathrm{NA}=10 \mathrm{~mm}$, Upper 1 to point $A=9 \mathrm{~mm}$, Upper 1 to $\mathrm{SN}=112^{\circ}$ ) and lower incisors were also proclined (Lower 1 to $\mathrm{NB}=8 \mathrm{~mm}$, Lower 1 to A-Pogonion Line $=4 \mathrm{~mm}$ and $\left.\mathrm{IMPA}=104^{\circ}\right) \cdot{ }^{10-18}$

After thorough examination it was decided to approach her problem as bimaxillary dentoalveolar protrusion correction, with emphasis on maximum anchorage conservation.

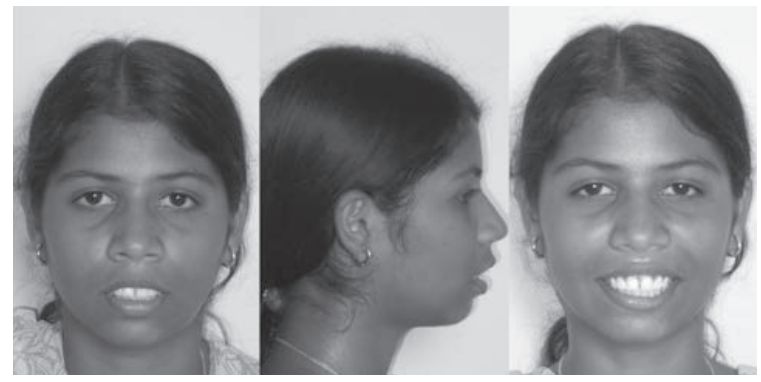

Figure 3: Pre-treatment extra-oral images

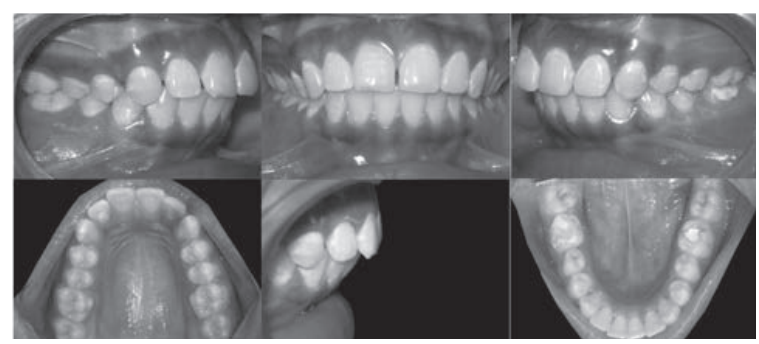

Figure 4: Pre-treatment intra-oral images
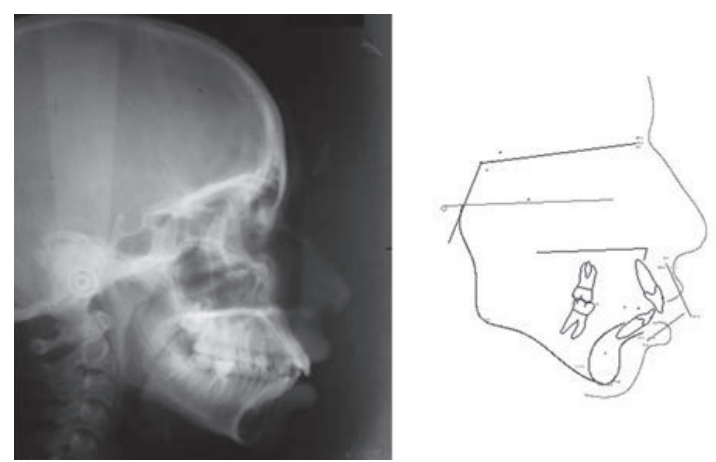

Figure 5:Pre-treatment lateral cephalogram and tracing images

Treatment Objectives: The treatment objectives were to (1) obtain a normal profile line to nose relationship and a normal $Z$ angle, (2) obtain normal canine and incisal guidance, (3) correct the bimaxillary dentoalveolar protrusion, (4) obtain lip competency without strain.

Treatment Plan: It was decided to extract all four first bicuspids based on Merrifield's total space analysis to determine space requirements, retract upper and lower 
anteriors into the extraction space with maximum anchorage conservation. Thereby achieving the dental and facial profile correction.

Treatment Progress: All teeth were bonded and banded with $0.022 \mathrm{MBT}$ prescription pre-adjusted edgewise appliance. Trans-palatal arch was placed in the maxillary arch to reinforce anchorage and prevent inadvertent molar rotation caused due to moments generated by the closing loop archwire. Initial aligining was begun with co-ordinated 0.014" stainless steel co-axial archwires, nickel-titanium archwires were avoided during mechanotherapy. Leveling was achieved till 0.019 " x $0.025^{\prime \prime}$ stainless steel archwires. Retraction was performed employing the indigenously designed "Swan Loop" using TMA wires in the maxillary arch; while in the mandibular arch retraction was performed using "sliding mechanics" (Figure 6). After space closure, finishing was performed using coordinated TMA archwires using the guidelines given by Poling R. Total treatment time was 18 months.

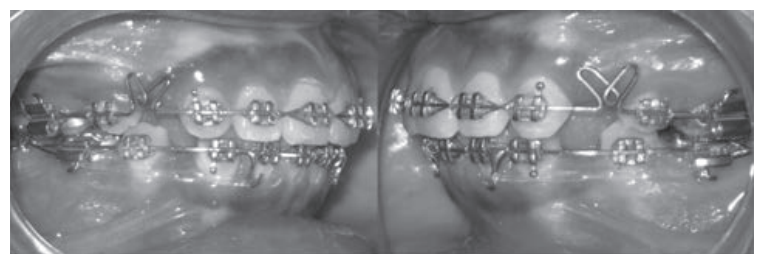

Fig 6: En-masse retraction employing Swan loop

Treatment Results: The post-treatment facial and intra-oral photographs illustrate the improvement in the patient's facial profile. Her midlines are now co-incident and in the middle of her face. Post treatment appraisal shows Class I molar and canine relationships, with normal overjet, overbite, incisal and canine guidance.

The post-treatment cephalometric radiograph and its tracing illustrate the changes achieved with treatment. The mandibular incisors were uprighted and retracted (IMPA $=95^{\circ}$, Lower 1 to $\mathrm{NB}=4 \mathrm{~mm}$, Lower 1 to A-Pogonion Line $=1 \mathrm{~mm}$ ). This uprighting caused the $Z$ angle to improve to $76^{\circ}$. The FMA angle remained unchanged at $26^{\circ}$.

The above case illustration presents the "Swan Loop" as an effective loop design for space closing archwires with an unpretentious configuration.

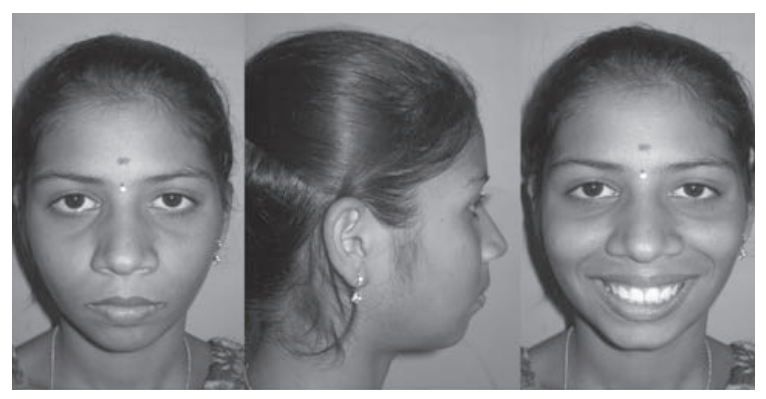

Figure 7:Post-treatment extra-oral images

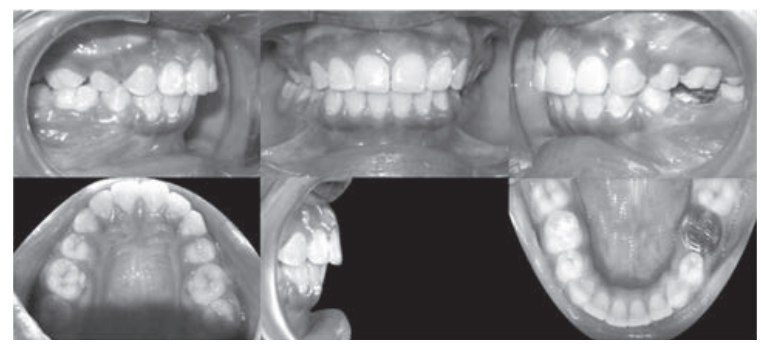

Figure 8:Post-treatment intra-oral images
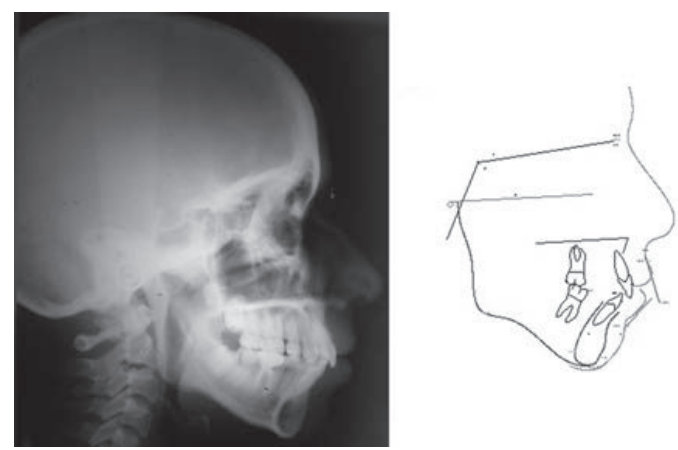

Figure 9: Post-treatment lateral cephalogram and tracing image 


\section{REFERENCES:}

1. Proffit WR, Fields HW: Contemporary Orthodontics, 3rd ed, Mosby Elsevier, 2000, pp 525.

2. Staggers JA, Germane N: Clinical considerations in the use of retraction mechanics, J. Clin. Orthod. 1991;25:364-369.

3. Tselepis M, Brockhurst P and West V C : The dynamic frictional resistance between orthodontic brackets and archwires, Am. J. Orthod. 1994;106:131-138.

4. Burstone CJ, Goldberg J : Beta Titanium: a new orthodontic alloy. Am. J. Orthod. 1980;7:2-9.

5. Siatkowski R E : Continuous arch wire closing loop design, optimization, and verification, Part I, Am. J. Orthod. 1997;112:393-402.

6. Siatkowski R E : Continuous arch wire closing loop design, optimization, and verification, Part II, Am. J. Orthod. 1997;112:487495.

7. $\quad$ Burstone C J : The segmented arch approach to space closure, Am. J. Orthod. 1982;82:361-378.

8. Gjessing P. Controlled retraction of maxillary incisors. Am J Orthod Dentofacial Orthop. 1992;101:120-3.

9. Vibhute PJ, Shrivastava S, Hazarey PV: The snail loop for low friction space closure. J Clin Orthod. 2007;42:233-234.

10. Nanda, R.: Biomechanics and Esthetic Strategies in Clinical Orthodontics. 1st ed. Elsevier Saunders, St. Louis, 2005, pp. 194-209

11. Halazonetis D.: Design and test orthodontic loops using your computer. Am J Orthod Dentofacial Orthop. 1997;111:346-348.

12. Burstone CJ. Application of Bioengineering to Clinical Orthodontic Practice. In: Graber TM, Vanarsdall RL, editors. Orthodontics: current principles and techniques. 4rd ed. Mosby-Elsevier, Missouri, 2005.pp. 293-330.

13. Steiner C C : Cephalometrics for you and me. Am J Orthod 1953;39(10):729-755.

14. Steiner C C : Cephalometrics in clinical practice. Angle Orthod 1959;29(1):8-29.

15. Tweed $\mathrm{CH}$ : The Frankfort mandibular incisors angle (FMIA) in orthodontic diagnosis, treatment planning and prognosis. Angle Orthod 1954;24:121-169.

16. Jacobson A: The Witt's appraisal of jaw harmony. Am J Orthod 1975;67:125-134.

17. Merrifield L L : Differential Diagnosis with total space analysis. J Charles Tweed Found 1978;6:10-15.

18. Merrifield L L : The profile line as an aid in critically evaluating facial esthetics. Am J Orthod 1966:52:804-22. 